\title{
Annual Evaluation for the Independence of People's Bank of China: An Attempt of Fuzzy Quantization
}

\author{
Su Jing \\ Business School, University of International Business \\ and Economics \\ Beijing, China \\ sujingkelly@foxmail.com
}

\author{
Li Sirui \\ School of Banking and Finance, University of \\ International Business and Economics \\ Beijing, China \\ e-mail: li_sirui@hotmail.com \\ * Corresponding Author
}

\author{
Li Shunyun \\ School of Economics and Management, Xinan \\ University \\ Chongqing, China
}

\begin{abstract}
In the research field of central bank, Central Bank Independence (CBI) is usually the focus of attention. Since 2003, the president and management system of People's Bank of China (PBC), which is the central bank of China, have not changed. And traditional methods cannot apply to evaluating CBI change of PBC in this interval. This paper tries to select some related indexes and make an annually quantitative evaluation for the independence of PBC from 2003 to 2013. The research conclusion will provide basis for the future research on the relationship between CBI of PBC and monetary policy effect. Furthermore, it can offer support for the system perfection of central bank management.
\end{abstract}

Keywords-CBI; PBC;Central Bank; Fuzzy Quantization

\section{INTRODUCTION}

Central Bank Independence (CBI) is a kind of freedom or autonomy that the decision maker of monetary policies have to cope with directly influence from the politics and government in the process of monetary policies making and execution (Walsh, 2005). After People's Bank of China (PBC) divested commercial bank business and became completely central bank, its CBI has driven people's attention. Researchers have studied in the relationship between CBI of PBC and monetary policy effect and given many advices for system perfection of China central bank management.

There are many methods can evaluate the independence of PBC. Among them, the methods which apply to China include TOR method that evaluates CBI by calculating the average tenure of central bank president and the rate of change (Cukierman \& Webb, 1992), and LS method that uses standard questionnaire to evaluate CBI from three respects: target independence, political independence and economic independence (Loungani \& Sheets, 1997). However, because the president and management system of PBC has not changed after Xiao- chuan Zhou took up the position in 2002 and the government succession had been finished in 2003, the subdivided indexes has not changed. That makes correlational researches give a single evaluation to $\mathrm{CBI}$ of PBC in this interval (Guo, 2011). But in general, CBI is almost impossible to keep invariant during such a long interval. So, the attempt of quantitative evaluation for annual CBI of PBC can complement the traditional methods and offer more detailed basis for the system perfection of central bank management.

\section{INDEX SELECTION OF CBI ANNUAL EVALUATION}

\section{A. Basic Principle of Index Selection}

To ensure the validity of concept construction, the selected indexes should originate from existing CBI evaluation systems. Considering that LS method is most applicable for $\mathrm{PBC}$, this paper select indexes from its three respects. But because of the political independence indexes have not changed in this period, the indexes will be mainly selected from target independence and economic independence.

Besides the validity of concept construction, the involved data should be complete, continuous and comparable. And the same set of data should be published by same subject; have same statistical caliber and time interval. That is the guarantee for accuracy of evaluation result.

Furthermore, the selected indexes should have high quantization degree or be easy to quantify. That can improve the objectivity of evaluation result.

\section{B. Contents of Internal Logic Index}

According to the principles above, this paper choose three indexes. 
TABLE I. FUNDAMENTAL CONTENTS OF INDEX

\begin{tabular}{|c|c|}
\hline Index & Content \\
\hline $\begin{array}{c}X_{1} \text { (Target } \\
\text { Independence) }\end{array}$ & $\begin{array}{l}\text { Non-consistence between current recognition } \\
\text { degree to economic growth in government work } \\
\text { report and increment of base money in next period. }\end{array}$ \\
\hline $\begin{array}{r}X_{2} \text { (Economic } \\
\text { Independence) }\end{array}$ & $\begin{array}{l}\text { Non-consistence between current ease degree of } \\
\text { monetary policy in government work report and } \\
\text { increment of base money in next period. }\end{array}$ \\
\hline$X_{3}$ (Mixed) & $\begin{array}{l}\text { Annual correlation between monthly total financial } \\
\text { deficit and monthly increment of base money. }\end{array}$ \\
\hline
\end{tabular}

$X_{1}$ : This index comes from LS target independence measurement. The standard question is that whether currency stability is listed as the central target of central banks' macroeconomic policies. It is shown as absolute value of difference between the standardized values of current recognition degree to economic growth in government work and increment of base money in next period. Bigger the value is, more freedom PBC will have. In fact, Chinese government always identify economic growth as the essential target although the degree is different. But that is inconsistent with the target of currency stability. Though PBC works as a part of the State Council, it also has autonomy in execution. So the degree of such non-consistence is positively correlated with $\mathrm{CBI}$

$X_{2}$ : This index comes from LS economic independence measurement. The standard question is that whether central banks is restricted to government in execution of monetary policies. It is shown as absolute value of difference between the standardized values of current ease degree of monetary policy in government work report and increment of base money in next period. Bigger the value is, more freedom $\mathrm{PBC}$ will have. In practice, if $\mathrm{CBI}$ is bigger, the central bank will have more autonomy in monetary policy. So the degree of such nonconsistence is positively correlated with CBI.

$X_{3}$ : This index comes from mixed LS measurement. It is shown as correlation coefficient of monthly total financial deficit and monthly increment of base money. This correlation coefficient lies between $0-1$, and is negatively correlated with CBI. On the one hand, controlling the scale of fiscal expenditures is the main target for government, but not for central bank. So this index can show the non-consistence of target between PBC and government. On the other hand, total financial deficit includes central government and local governments. So, with the special political structure of China, local administrator (such as secretary of provincial CPC and nomarch), minsters of central government which have the same administrative rank as the president of $\mathrm{PBC}$ have the power to influence the decision of monetary policies, when finance strain is pricked up. That means this index can measure the ability of PBC to countermove government intervention. If the execution of monetary policies is in line with the intention of government, $\mathrm{PBC}$ will supply more base money when the scale of fiscal deficits become larger. That means the correlation coefficient is positively correlated with CBI.

Additionally, the data extraction and calculation of indexes is based on their value, but not ratio. Firstly, because of the lack of logical rationality, it is meaningless to measure the three sets of indexes including recognition degree to economic growth in government work report, ease degree of monetary policy in government work report and total financial deficit. In the second place, the increment of base money is more convincing than its growth rate in practice. Finally, extracting value is a direct and convenient way. To some extent, that can avoid errors and omissions of data processing.

Besides, to ensure the integrity of the data, the data of three indexes above will be extracted in statistical interval 2002-2014, and the evaluated in interval 2003-2013.

\section{ANNUAL EVALUATION FOR CBI OF PBC FROM 2003 TO 2013}

\section{A. Data Extraction and Processing}

\section{1) Data Extraction}

The data of annual increment of base money, monthly increment of base money and monthly total financial deficit are extracted from CEInet Statistics Database and CSMAR Solution.

The quantitative data of recognition degree to economic growth in government work report is got from text mining. This paper use Replace Pioneer to extract sentences including "growth" from annual government work report, then screen the result based on semanteme and reserve the sentences which are related with economic growth. The counting result of reserved sentences represents the recognition degree to economic growth in government work report. That is a set of positive data.

The ease degree of monetary policy in government work report is quantified by 1-4 scale method. If the tendency of monetary policies are expressed as "appropriately stringent", the scale is 1; when the expression is "appropriately easy", the scale is 4 ; if the tendency is "prudent", the scale of the year will be judge by actual situation.

2) Data Processing

In accordance with the contents of indexes, make Min-Max standardized processing to annual data of recognition degree to economic growth in government work report, ease degree of monetary policy in government work report and increment of base money. Because all the indexes are in positive correlation with CBI, the annual data should be processed by formula $C_{i j}{ }^{\prime}=\frac{C_{i j}-C_{i(\min )}}{C_{i(\max )}-C_{i(\min )}}, C_{i j}{ }^{\prime}$ is value of standard index and $C_{i j}$ is value of original data.

After standardized processing, $X_{1}$ and $X_{2}$ can be got by subtracting related indexes, and $X_{3}$ can be got by calculating the correlation coefficient.

For convenience, the data of $X_{1} X_{2}$ and $X_{3}$ should be processed again, the results is as follows. 
TABLE II. DATA AFTER PROCESSING

\begin{tabular}{|c|c|c|c|}
\hline Year & $X_{1}$ & $X_{2}$ & $X_{3}$ \\
\hline 2003 & 0.5685 & 0.5146 & 0.1694 \\
\hline 2004 & 0 & 0.5384 & 0.0404 \\
\hline 2005 & 0.3264 & 0.1811 & 0 \\
\hline 2006 & 0.7535 & 0.2864 & 0.0545 \\
\hline 2007 & 0.9137 & 1 & 0.0178 \\
\hline 2008 & 0.3819 & 0.1204 & 0.1708 \\
\hline 2009 & 0 & 0 & 0.0348 \\
\hline 2010 & 1 & 0.0899 & 0.0563 \\
\hline 2011 & 0.8164 & 0.0755 & 1 \\
\hline 2012 & 0.3464 & 0.0561 & 0.754 \\
\hline 2013 & 0.1614 & 0.254 & 0.0836 \\
\hline
\end{tabular}

\section{B. Analysis of Evaluation Results}

\section{1) Evaluation Results of $C B I$ of $P B C$}

Calculating the arithmetic mean of indexes, the evaluation results of annual CBI of PBC can be got in target interval.

TABLE III. ANNUAL CBI OF PBC FROM 2003 TO 2013

\begin{tabular}{|c|c|}
\hline Year & Result \\
\hline 2003 & 0.4175 \\
\hline 2004 & 0.1929 \\
\hline 2005 & 0.1692 \\
\hline 2006 & 0.3648 \\
\hline 2007 & 0.6438 \\
\hline 2008 & 0.2244 \\
\hline 2009 & 0.0116 \\
\hline 2010 & 0.3821 \\
\hline 2011 & 0.6306 \\
\hline 2012 & 0.3855 \\
\hline 2013 & 0.1664 \\
\hline
\end{tabular}

1.0000

0.9000

0.8000

0.7000

0.6000

$0.5000 \quad 0.4175$

0.4000

0.3000

0.2000

0.1000

0.0000

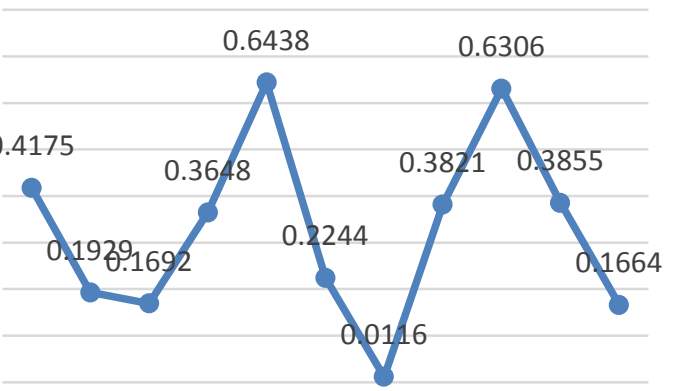

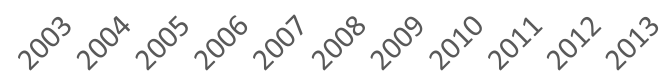

Figure 1. The Change of Annual CBI of PBC from 2003 to 2013
In 2003, CBI of PBC was in a moderate level, and kept going down in 2004 and 2005. Then, from 2006 to 2007, CBI of PBC increased rapidly and reached the peak in target interval. In 2008 and 2009, CBI of PBC dropped very sharply and reached the rock bottom. After that, CBI of PBC kept rising during 2009 to 2011, and dropped in 2012 and 2013.

It must be point out that the evaluation results above is the relative results in target interval, the value of single year is meaningless. Furthermore, the results is fuzzy, the meaning of rank is much more useful than the value.

2) Test and Application of Annual CBI Evaluation Results

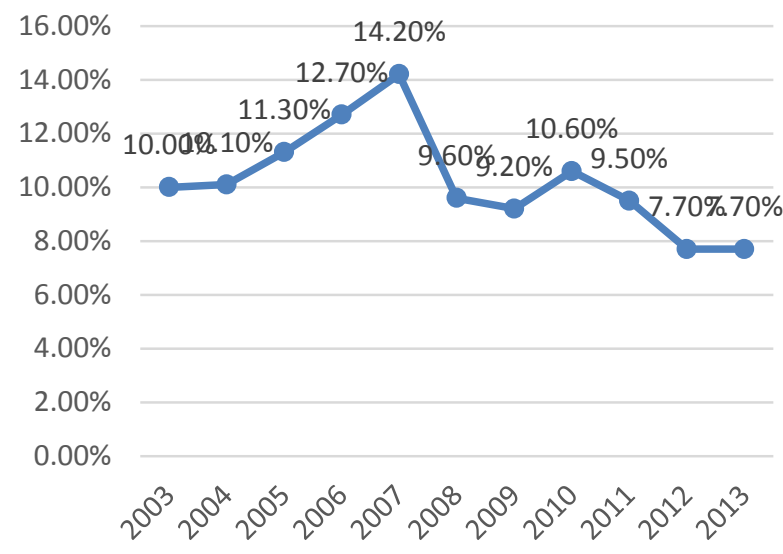

Figure 2. Change of Chinese GDP Growth Rate from 2003 to 2013

Comparing with the GDP growth rate, it can be hazily regarded that $\mathrm{CBI}$ of $\mathrm{PBC}$ will keep at high level when the GDP growth is rapid and will keep at low level when the GDP growth is slow. In the year which has a negatively economic growth, the central government may mobilize resources to promote economic growth. That means the central government will require $\mathrm{PBC}$ for cooperation. So the CBI of PBC is low at this situation. Of course, this logic is just a possible speculation, but can also provide validation for the evaluation results to some extent.

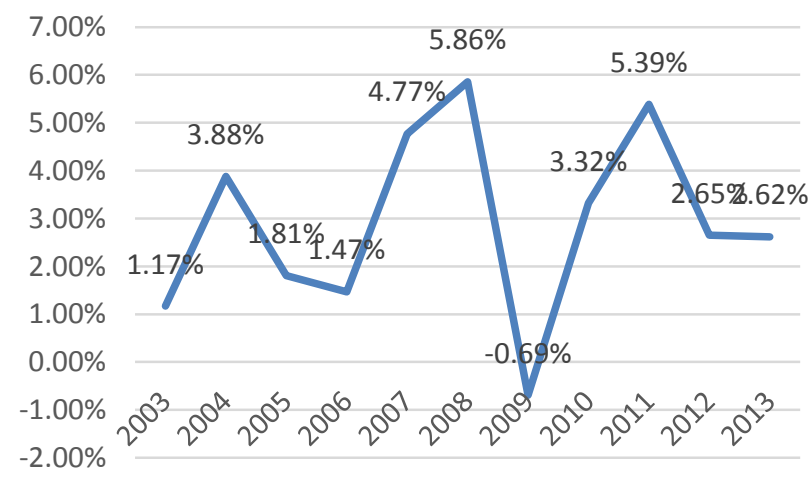

Figure 3. Change of Chinese Inflation Rate from 2003 to 2013

Currency stability is the most essential target of monetary policies. The traditional theory thought that CBI is negatively related with inflation rate. However, the situation of China may be different. Comparing with Figure 3, it is easy to find that $\mathrm{CBI}$ of $\mathrm{PBC}$ is almost not 
related with inflation rate. That is obviously different with traditional theory. Analyzing to a certain point, PBC is influenced by the government in the decision and execution of monetary policies resulting from its low in general CBI level. As the analysis above, the central government of China always list economic growth as its essential target. That need to make PBC abandon the target which currency stability. It should be specially explained that this logic is just a reasonable guess. It is need to make a individual analysis for this question to get more reliable results.

\section{LIMITATION AND NEXT RESEARCH DIRECTIONS}

The presented method in this paper is an attempt of short-term change in CBI during the period that the indexes of traditional methods have not changed. There are some limitation and room for improvement of this attempt.

Firstly, because of the lack of reliable data, the tentative method above only selects three indexes as the basis of CBI evaluation. That might cause the problem of unstable result. Addition or lessen of indexes will visibly affect the evaluation results. In order to get stable results, it is necessary to extract more indexes as the support. That is the focus in next step.

Secondly, the selection of indexes and the analysis of internal logic should be more rigorous. For example, in note 1 , although the view that regard 4000-billion-stimulus policies as the main reason of the huge base money issue have been accepted in general, the validity of concept construction also has room for consideration.

In the third place, the universality of the method above is not enough. It is not applicable for other central banks. It is a concerned direction in the future to improve the evaluation system to make the method can be used in other central banks of developing countries.

Finally, the attempt above just provide a method to evaluate $\mathrm{CBI}$ of $\mathrm{PBC}$ and the results. In fact, the purpose of evaluation of $\mathrm{CBI}$ of $\mathrm{PBC}$ is providing support to research the relationship between $\mathrm{CBI}$ of $\mathrm{PBC}$ and monetary policy effect and given policy suggestion. In this respect, there are many questions to be researched and solved.

\section{REFERENCES}

[1] Newman P, Milgate M, Eatwell J. "The New PalGrave A Dictionary OF Economics," Macmillan Publishers Limited, 2005.

[2] Khan A H, Khan H A, Dewan H. "Central bank autonomy, legal institutions and banking crisis incidence," International Journal of Finance \& Economics, vol. 18, pp. 51-73,2011.

[3] Ueda K, Valencia F. "Central bank independence and macroprudential regulation," Economics Letters vol. 125, pp. $327-$ 330,2014

[4] Alpanda S, Honig A. "The impact of central bank independence on the performance of inflation targeting regimes," Journal of International Money and Finance, vol. 44, pp. 118-135,2014.

[5] Arnone M, Romelli D. "Dynamic central bank independence indices and inflation rate: A new empirical exploration," Journal of Financial Stability, vol. 9, pp. 385-398,2013.

[6] Nolivos R D, Vuletin G. "The role of central bank independence on optimal taxation and seigniorage," European Journal of Political Economy, vol. 34, pp. 440-458,2014.

[7] LI Daokui. "The central bank independence is a futile superstition," Real Estate Information of China, vol. 6, pp. 73, 2012.

[8] Cukierman A, Webb S. "Measuring the Independence of Central Banks and Its Effect on Policy Outcomes," World Bank Review, vol. 6 , pp. 353-398,1992.

[9] Loungani P, Sheets N. "Central Bank independenee, infiation and growth in transition economies," Money Credit Banking, vol. 29 pp. 381-399, 1997.

[10] Guo Jiangning. "China's Central Bank Independence and the Inflation Rate Correlation Studies," Southwestern University of Finance and Economics,2011.

[11] Liu Xiliang, Xiao ling. "From Independence to Cooperation: the Trend of Central Banks," Journal of Finance, vol. 10, pp. 17-26, 2003.

[12] Guo Zhenlin. "The development trend of central bank independence," Shanghai Finance, vol. 11, pp. 6-9. 1992. 